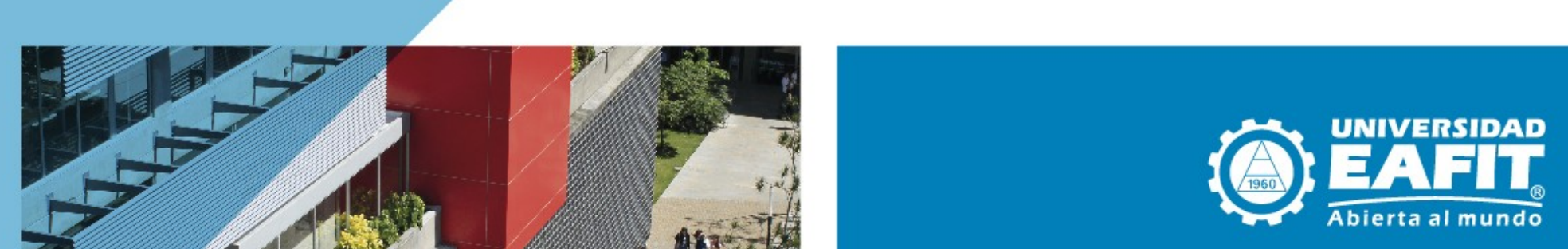

Escuela de Economía y Finanzas

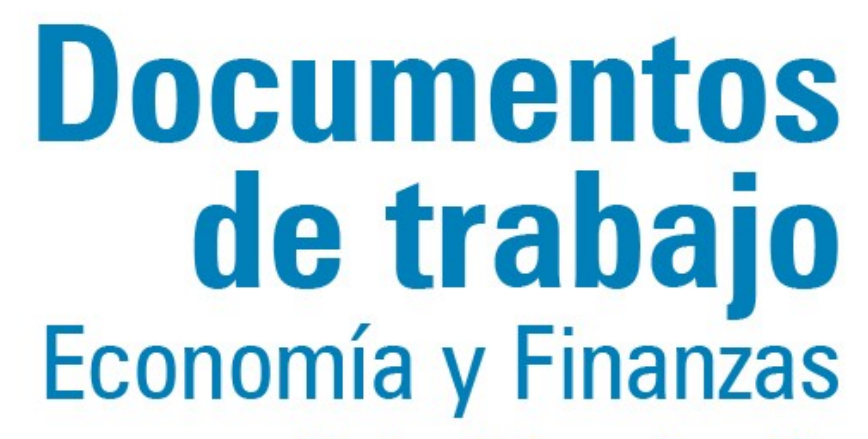

Centro de Investigación Económicas y Financieras

No. 17-14 Market and disposable top income shares adjusted 2017 by national accounts data

Thomas Goda, Santiago Sanchez

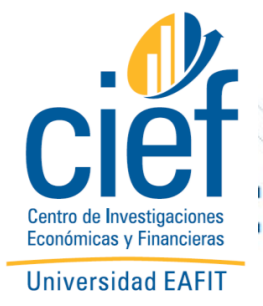




\title{
Market and disposable top income shares adjusted by national accounts data
}

\author{
Thomas Goda ${ }^{\mathrm{a}}$ and Santiago Sanchez ${ }^{\mathrm{b}}$
}

\begin{abstract}
This paper uses national accounts data to adjust market and disposable Top 10\% and Top 1\% household survey income shares for 39 developed and developing countries that are part of the Luxembourg Income Study (LIS). An additional novelty of this study is the distinction between labor and capital income. The obtained results suggest that for most countries top income shares are significantly higher than those reported in household surveys, which mainly underestimate top capital income. While the presented results should be treated with some caution, our easy-to-implement approach seems suitable for countries for which no tax data is available.
\end{abstract}

Key Words: top income shares, personal income inequality, income distribution, LIS household surveys, system of national accounts (SNA)

\section{JEL Classification: D31; E25}

\footnotetext{
${ }^{a}$ Universidad EAFIT, School of Economics and Finance, Carrera 49 Número 7 Sur 50, Medellín, Colombia; email: tgoda@eafit.edu.co; phone: (57) 42619500 - 8664 (corresponding author).

${ }^{\mathrm{b}}$ Universidad EAFIT, School of Economics and Finance, Carrera 49 Número 7 Sur 50, Medellín, Colombia; email: ssanch40@eafit.edu.co.

We would like to thank Germán Tabares for research assistance, and the participants of the first LIS/LWS Users Conference for their comments that enabled us to substantially improve the first draft of this paper.
} 


\section{Introduction}

Income inequality within countries demonstrated a sharp upward trend from 1975 onwards. This is especially true for developed countries, but also when measured at the global level (OECD, 2015; Goda, 2016). Recent research shows that this increase in inequality has had adverse effects on health and social cohesion (Wilkinson and Pickett, 2011; Stiglitz, 2012; Atkinson, 2015), financial stability (Kumhof et al., 2015; Stockhammer, 2015; Goda et al., 2017), and economic growth (Herzer and Vollmer, 2012; 2013; Halter et al., 2014; Onaran and Galanis, 2014). Moreover, it negatively influences democratic decision-making processes by augmenting the lobbying power of the elites (Esteban and Ray, 2006; Acemoglu and Robinson, 2008; Crotty, 2012; Gilens and Page, 2014). Consequently, there is a growing perception that the topic needs much more attention and is among the most pressing current global challenges (Obama, 2011; Lagarde, 2013; OECD, 2015; Piketty, 2015; Oxfam, 2014; 2017).

Typically, within-country income inequality estimates are based on household survey data. However, it is well documented that these tend to underestimate income at the top of the distribution, so that an increasing number of studies attempt to adjust the top income data that is reported in household surveys (Atkinson and Piketty, 2007; 2010; Atkinson et al., 2011; Lakner and Milanovic, 2013; 2016; Ruiz and Woloszko, 2016; Alvaredo et al., 2017b). For this adjustment process tax data is often used, which has the disadvantage that the coverage, definition, and valuation of income depends on each nation's tax laws and that many assumptions and data interpolations are necessary to homogenize the data (see Alvaredo et al., 2017a). Moreover, tax data is not readily available for many countries, and it is well known that households with especially high income often avoid and evade tax payments.

A second limitation of the existing literature is that it does not distinguish between inequality prior to and after government intervention (i.e. existing estimates focus either on pre-tax or disposable income). The aim of this paper is to adjust household survey market and disposable top income shares for a sample of 39 developed and developing countries. Market income (i.e. labor and capital income) refers to income prior to government intervention, while disposable income (market income net of social security contributions and income taxes, plus transfer income) refers to income after government intervention.

More specifically, we use a Pareto interpolation method to adjust the top income data from the latest available household surveys of the Luxembourg Income Study (LIS) with the 
respective household income aggregates from the System of National Accounts (SNA). The reliance on SNA data has the advantage that it allows for the retrieval of estimates for countries for which tax data is not available, which is the case for more than half of our sample countries, and that it is relatively easy to implement. An additional novelty of our paper is the distinction between capital and labor income during the adjustment process. We expect that most of the adjustment will take place due to underreported capital income on the grounds that wealth is highly concentrated at the top (see Piketty (2014) and Goda (2017)).

Our results suggest that for most countries the adjusted top income shares are significantly higher than those reported in LIS household surveys. This is especially true for the developing countries of our sample, whereas in Canada, Japan, and the Nordic countries no or only relatively small adjustments are necessary. The main adjustment takes place due to an underestimation of top capital income. A comparison with existing top income share estimates suggest that our methodology neither yields an upward or downward bias. However, the presented top income shares should be treated as rough estimates, considering the available data and the issue that no objective criteria exist to define how much of the income difference between national accounts and household surveys should be attributed to top earners. Having said this, the obtained results suggest that our easy-to-implement approach is a suitable way to derive adjusted top income shares for countries that do not provide or have reliable tax data.

The remainder of this paper is organized as follows. Section Two briefly discusses prevalent issues concerning household surveys and the limitations of existing top income estimates. Section Three presents the research design used to adjust the household survey data with official national accounts data. Section Four presents the adjusted market and disposable income shares, and compares the latter with the top income share estimates of the World Wealth \& Income Database (WID) ${ }^{1}$. Section Five draws conclusions.

\footnotetext{
${ }^{1}$ The WID project was founded under the name World Top Incomes Database (WTID).
} 


\section{Limitations of existing top income estimates}

Data on income inequality is retrieved mainly from household surveys, which are known to under-represent both low income and top income households; very poor households often lack a registered address, and very rich households are not easily accessible and tend not to respond. Hence, household surveys typically oversample top income households. However, particularly among the upper tail of the distribution, misreporting is also prevalent, whether deliberately or due to ignorance. It is thus well established that inequality estimates based on household survey data underestimate the degree of income at the very top (Groves and Couper, 1998; Atkinson and Brandolini, 2001; Deaton, 2005; Atkinson and Piketty, 2007).

To adjust household survey top income shares, tax data is typically used (Atkinson and Piketty 2007; 2010). This data has the advantage that its declaration is not voluntary so that, in principle, all top income households should be covered by the sample. However, it has the disadvantage that the definition and valuation of income depends on each nation's tax laws, that non-tax filers are not included, and that the very rich sections of society, often successfully, try to avoid and evade tax payments (Leigh, 2007; Lakner and Milanovic, 2013; 2016). The latter point is of particular importance: Zucman (2013) estimates that \$5.9 trillion of assets are held offshore and that at least $75 \%$ of these assets are not reported, whereas other estimates suggest that rich individuals are hiding between US\$ 12 trillion (Palan et al., 2010) and US\$ 21 trillion (Henry, 2012) in tax havens.

To overcome these issues, the newest version of the widely used WID attempts to homogenize the observation units (adults that are $\geq 20$ years old), and to use generalized Pareto interpolation methods to correct the reported taxable income to match the income totals that are reported in the national accounts (see Alvaredo et al., 2017a). Moreover, it aims to correct for tax underreporting by considering Zucman's (2013; 2014) offshore wealth estimates. However, even with these considerable improvements, WID's reliance on tax data still has the disadvantage that this is not available for all countries, and that its usage requires many assumptions and data interpolations. 
Accordingly, Lakner and Milanovic (2013; 2016) prefer to solely rely on systems of national accounts data to adjust disposable top income shares. ${ }^{2}$ SNA data has the advantage that it tracks all money flows within an economy, including the income that goes to top income households (Deaton, 2005). Moreover, SNA data is readily available for most countries, its reporting guidelines are standardized across all countries, and the adjustment is easy to implement. Accordingly, Campos Vázquez and Chavez (2016) use a similar approach to adjust Mexico's top income shares. However, Lakner and Milanovic (2016) find that their methodology in some cases leads to adjustments that seem excessive.

Finally, Ruiz and Woloszko (2016) neither rely on tax nor on SNA data but instead use West's (1986) conditional likelihood estimator to adjust pre-tax household survey income. To be able to do so, they assume that the Pareto law applies for all incomes above the median. This assumption is questionable, given that most literature finds that the Pareto law only applies to top incomes and that other distribution types are more appropriate to calculate incomes below the top.

Despite their different methodologies, existing studies have in common that they do not distinguish between different types of income. This is an important limitation, given that it can be expected that capital income is more important for top income households than for 'ordinary' households, because the former are the ones that own most financial assets (see Shorrocks et al. (2016) and Goda (2017)). Another limitation of existing studies is that they do not consider pre-government intervention inequality (i.e. market top income shares).

\section{Methodology}

\subsection{Market and disposable income sources}

As mentioned in the introduction, this study considers two different income concepts: market income and disposable income. To obtain the latest available household survey income, LIS's database is used because it is "the largest available income database of harmonised microdata" (LIS, 2017). The survey data is obtained as income percentile averages $\left(P_{1} \ldots P_{100}\right)$. For the

\footnotetext{
${ }^{2}$ Please note that, depending on data availability, Lakner and Milanovic $(2013 ; 2016)$ use a mix of disposable income and consumption data for their estimates.
} 
adjustment process, on the other hand, SNA household income aggregates are derived from UNdata, OECD.stat, and Eurostat (see Table 1 for an overview). To make LIS's survey data and the SNA aggregates comparable, LIS's income percentiles are multiplied by the one percent of total households.

Table 1: Sample overview

\begin{tabular}{|c|c|c|c|c|c|}
\hline Country & Year & SNA Source & Income Estimates & $\begin{array}{l}\text { Number of } \\
\text { Households }\end{array}$ & $\begin{array}{c}\text { Household Size } \\
\text { Source }\end{array}$ \\
\hline Australia & 2010 & OECD & B2n, B3n, D1, D4 & $7,760,332$ & UN \\
\hline Austria & 2013 & Eurostat & B3n & $3,474,800$ & IPUMS \\
\hline Belgium & 2000 & Eurostat & $\mathrm{B} 3 \mathrm{n}$ & $4,384,200$ & IPUMS \\
\hline Brazil & 2013 & UN & B3n & $58,145,560$ & IPUMS \\
\hline Canada & 2010 & OECD & B2n, B3n, D1, D4 & $13,320,600$ & UN \\
\hline China & 2002 & UN & $\mathrm{B} 3 \mathrm{n}$ & $355,613,241$ & IPUMS \\
\hline Colombia & 2013 & UN & B3n & $10,570,900$ & UN \\
\hline Czech Republic & 2013 & Eurostat & B3n & $4,582,800$ & IPUMS \\
\hline Denmark & 2013 & Eurostat & B3n & $2,313,700$ & IPUMS \\
\hline Egypt & 2012 & UN & $\mathrm{B} 3 \mathrm{n}$ & $17,404,140$ & IPUMS \\
\hline Estonia & 2013 & Eurostat & $\mathrm{B} 3 \mathrm{n}$ & 582,000 & UN \\
\hline France & 2010 & Eurostat & B3n & $27,205,100$ & IPUMS \\
\hline Finland & 2013 & Eurostat & B3n & $2,571,000$ & IPUMS \\
\hline Germany & 2013 & Eurostat & B2n, B3n & $39,410,700$ & IPUMS \\
\hline Greece & 2013 & Eurostat & B3n & $4,352,600$ & IPUMS \\
\hline Guatemala & 2006 & UN & B3n & $2,921,300$ & NAKONO \\
\hline Hungary & 2012 & Eurostat & B3n & $4,085,500$ & IPUMS \\
\hline Iceland & 2010 & UN & B3n & 128,700 & OECD \\
\hline India & 2011 & UN & B3n & $230,126,806$ & IPUMS \\
\hline Ireland & 2010 & Eurostat & B2n, B3n & $1,689,000$ & IPUMS \\
\hline Italy & 2014 & Eurostat & B3n & $24,669,800$ & IPUMS \\
\hline Japan & 2008 & UN & B3n & $51,842,300$ & UN \\
\hline Luxembourg & 2007 & UN & B3n & 204,900 & IPUMS \\
\hline Mexico & 2012 & UN & B3n & $29,036,410$ & IPUMS \\
\hline Netherlands & 2013 & Eurostat & B3n & $7,548,800$ & IPUMS \\
\hline Norway & 2013 & Eurostat & B3n & $2,224,200$ & UN \\
\hline Peru & 2013 & UN & P51c, B3n & $8,216,750$ & IPUMS \\
\hline Poland & 2013 & UN & B3n & $13,660,100$ & IPUMS \\
\hline Romania & 1997 & UN & B3n & $7,320,160$ & IPUMS \\
\hline Russia & 2013 & UN & B3n & $54,560,600$ & UN \\
\hline Serbia & 2010 & UN & $\mathrm{B} 3 \mathrm{n}$ & $2,487,900$ & UN \\
\hline Slovak Republic & 2013 & Eurostat & B3n & $1,754,100$ & IPUMS \\
\hline Slovenia & 2012 & Eurostat & $\mathrm{B} 3 \mathrm{n}$ & 842,300 & IPUMS \\
\hline South Africa & 2012 & UN & B3n & $17,258,500$ & IPUMS \\
\hline South Korea & 2012 & OECD & B3n & $11,202,500$ & UN \\
\hline Spain & 2013 & Eurostat & B3n & $18,212,400$ & IPUMS \\
\hline Sweden & 2005 & Eurostat & B3n & $4,248,700$ & IPUMS \\
\hline United Kingdom & 2013 & Eurostat & B2n, B3n & $27,610,900$ & IPUMS \\
\hline United States & 2013 & UN & B3n & $119,778,900$ & IPUMS \\
\hline
\end{tabular}


SNA data has the advantage that the reporting rules are standardized across countries, that it is easily accessible and that it captures all income flows. It considers, for example, the income from the sale of illegal drugs and stolen property, which is unlikely to be reported in household surveys and is definitely not reported in tax records. Having said this, the reliance on SNA data also has some disadvantages. First, countries often do not report data for income subcategories. Second, although SNA has standardized reporting rules, the compilation of the data differs between countries, which means that, for example, the distinction between self-employed and firms differs between countries. Moreover, it is not clear how reliable the information on mixedincome is, given that it is a residual that balances the national account. However, despite these issues, the reliance on SNA data is an interesting alternative way to adjust survey top income shares, given that the adjustment procedure is easy to implement and that it allows for the retrieval of estimates for countries for which tax data is not available (this is the case for $54 \%$ of our sample countries).

SNA data can be used for the adjustment of household survey data, given that the sum of market household survey income ${ }^{3}$ in the $i$-th country is approximately equivalent to the following SNA primary resource incomes of households (sector S.14):

$$
\text { Market Income }_{i}=D 1_{i}+\left(D 4_{i}+B 2 n_{i}\right)+B 3 n_{i}
$$

where $D 1$ is compensation of employees, $D 4$ is property income, $B 2 n$ is net operating surplus (i.e. rental income from housing), and $B 3 n$ is net mixed income (i.e. self-employed income). In other words, $D 1$ is labor income, $(D 4+B 2 n)$ is capital income, and $B 3 n$ is a mixture of labor and capital income.

Total disposable household survey income ${ }^{4}$ in the $i$-th country, on the other hand, is approximately equivalent to the following SNA secondary resource income of households:

$$
\text { Disposable } \text { Income }_{i}=B 6 n_{i}
$$

\footnotetext{
${ }^{3}$ The labor income that is reported in LIS (il) includes all "monetary payments and value of non-monetary goods and services received from dependent employment" and "profits/losses and value of goods for own consumption from self-employment", whereas LIS capital income (ic) relates to "monetary payments from property and capital (including financial and non-financial assets).

${ }^{4}$ The disposable income that is reported in LIS (dhi) is the sum of labor income (il), capital income (ic) and transfer income (it), minus income taxes (xiti) and social security contributions (xits).
} 
where $B 6 n$ is net disposable income (which includes market income, social benefits, net private transfers, net social contributions, and taxes on income and wealth).

Unfortunately, only gross values of mixed income (B3g) are publicly available. Furthermore, the consumption data of fixed capital on gross mixed income (P51c2) is also unavailable. However, total household consumption of fixed capital (P51c) data is available for most countries. Hence, we assume that households' $P 51 c 2$ is related to the proportion of mixed income to total household income that is affected by depreciation $(\overrightarrow{P 51 c 2}=P 51 c$ * $(B 2 g /(B 2 g+B 3 g))$. The estimated consumption of fixed capital on mixed income is then used to obtain net mixed income $(B 3 g-P \overline{51 c} 2)$.

To include as many countries as possible in our sample we make some further estimations of SNA data (see Table 1 for an overview), by considering the values of countries with similar characteristics to those with missing data as a benchmark. To be more precise, for Australia, Canada and South Korea only the data of combined income of households and non-profit institutions is available (S.14+S.15). In the case of Australia and Canada we assume that the proportion of S.14 on this sum is the same as in the USA (98\%), while Japan is used as benchmark in the case of South Korea (96\%). Furthermore, we assume for Australia and Canada that $B 3 g(11 \%), D 1(71 \%)$ and $D 4(11 \%)$ have the same proportion of primary income $(B 5 g)$ than in the USA.

For Germany, Ireland and the UK only the data for the sum of $B 2 n+B 3 n$ is available. In the case of Germany, we assume that $B 3 n$ has the same proportion of this sum as in Austria (62\%), while for Ireland and the UK we take the same proportion as the one found in the USA (57\%). Finally, for Brazil, Colombia, Guatemala, Peru and China the data of P51c is not available. For the four Latin American countries the same rate of depreciation as in Mexico is assumed (12\%), while for China the rate for India is taken as a benchmark (11\%). After these adjustments, both LIS and SNA data is available for a sample of 39 countries.

\subsection{Adjustment of LIS top income shares}

Each country's household survey income is subtracted from the household income listed in (1) and (2). The obtained difference is the so called residual. A positive residual implies that the income of households that is reported in SNA is higher than the income that is reported in 
LIS's household surveys, i.e. that especially income at the top is underreported in the survey (as discussed in Section 2). In all but five countries (Canada, Finland, Japan, Iceland, and Sweden) the residual is positive. The five countries with a negative residual have in common that their survey is combined with information from administrative tax registers. In line with Lakner and Milanovic $(2013 ; 2016)$ no adjustments are made when the residual is negative.

It is well established in the literature that the income distribution at the top follows a Pareto distribution. Hence, we first use the residual to calculate the Pareto coefficient, and then distribute the residual to each percentile of the Top $10 \%$ income according to the calculated Pareto coefficient. Relative income shares of the Pareto distribution can be expressed as follows (see Atkinson, 2007):

$$
\frac{S_{i}}{S_{j}}=\left(\frac{H_{i}}{H_{j}}\right)^{\frac{\alpha-1}{\alpha}}
$$

where $S_{i}$ is the $i$-th LIS top income share adjusted by the residual, $S_{j}$ is the $j$-th LIS top income share adjusted by the residual, and $H_{i}$ and $H_{j}$ are the respective proportions of the population that hold these income shares.

Given that $S_{i}, S_{j}, H_{i}$ and $H_{j}$ are known, the Pareto coefficient $(\alpha)$ can be estimated as follows:

$$
\hat{\alpha}=\frac{1}{1-\left(\frac{\ln \left(S_{i}\right)-\ln \left(S_{j}\right)}{\ln \left(H_{i}\right)-\ln \left(H_{j}\right)}\right)}
$$

We use the Top $10 \%$ and Top $5 \%$ income shares (i.e., $H_{i}=0.05$ and $H_{j}=0.10$ ) to estimate the Pareto coefficient, which is in line with Atkinson (2007). After having obtained the Pareto coefficient from (4), the cumulative top shares are derived solving for $S_{i}$ in (3). The shares of each percentile below the highest share $\left(P_{100}\right)$ can then easily be calculated by subtracting from each percentile share the next highest percentile share $\left(P_{100-n}=S_{1+n}-S_{1+n+1}\right)$.

As mentioned in the introduction, a novelty of our study is that we adjust capital and labor income separately. To do so we need to calculate individual residuals for both income types. Before doing so, one has to decide how to distribute mixed income (B3n). Alvaredo et al. (2017a) argue that a 70\% labor and 30\% capital income split is valid as a rule of thumb. However, it is likely that the labor income percentage of mixed income is higher in countries 
that have a large informal sector. Hence, we use a 90-10 split for countries with a relatively large informal sector ${ }^{5}$ and a $70-30$ split for the remaining countries. ${ }^{6}$

Next, one has to decide how much of the labor income and capital income residual should be assigned to the Top 10\% and Top 5\% respectively. Lakner and Milanovic $(2013 ; 2016)$ allocate $100 \%$ of the residual to the top decile. However, it is very likely that underreporting not only takes place at the top. Hence, Campos Vázquez and Chavez (2016) allocate 78\% of the residual to the Top 10\% and the rest to the ninth decile (lower bound scenario). Taking advantage of the differentiation between labor and capital income, we choose a different approach: we assign $90 \%$ of the capital income residual to $S_{10}$ (and $95 \%$ of this $90 \%$ to $S_{5}$ ), and $50 \%$ of the labor income residual to $S_{10}$ (and $66 \%$ of this $50 \%$ to $S_{5}$ ).

The justification for this approach is that it is well documented that capital income is highly concentrated at the very top, while labor income is much more evenly distributed. Moreover, these percentages are similar to the LIS data in countries that have negative residuals and they ensure that no country experiences a downward adjustment. ${ }^{7}$ Finally, the residual for disposable income is assigned according to each country's post-adjustment $S_{10}$ and $S_{5}$ market income percentages (on average, $73 \%$ of the disposable income residual is allocated to the Top 10\%, while $85 \%$ of this $73 \%$ is allocated to the Top $5 \%$ )

It should be stressed that the applied percentages are imprecise. However, they are reasonable considering the information available, and to the best of our knowledge no criteria exist that would aid in deciding precisely how the residual should be spread among the distribution. Moreover, both the household survey data and the SNA data have a degree of imprecision that makes it questionable whether a more sophisticated methodology yields more reliable estimates than the presented approach.

\footnotetext{
${ }^{5}$ In the following countries the share of informal employment is relatively high (i.e. above 20\%): Brazil, Colombia, Greece, Guatemala, India, Italy, Mexico, Peru, Poland, Romania, South Africa and South Korea.

${ }^{6}$ Please note that the obtained results do not change substantially if slightly different splits are taken instead (e.g. 80-20).

${ }^{7}$ Especially in the case of labor income, in some countries a lower percentage of the residual going to the Top $10 \%$ and Top 5\% would result in a downward adjustment of top income shares.
} 


\section{Results}

\subsection{Market income estimates}

Figure 1 shows the Top 10\% labor and capital income shares with and without adjustment. The adjustment is relatively strong in many countries and also changes the order of countries. For example, according to LIS's household survey data Sweden (49\%), South Africa (47\%), Egypt (43\%), Guatemala and India (42\%) are the five most unequal countries of the sample. After the adjustment Sweden drops out of the top ten and the ranking of the top five changes to India (69\%), Mexico (62\%), Guatemala (61\%), South Africa (59\%), Romania and Egypt (58\%).

Figure 1: Top 10\% market income shares

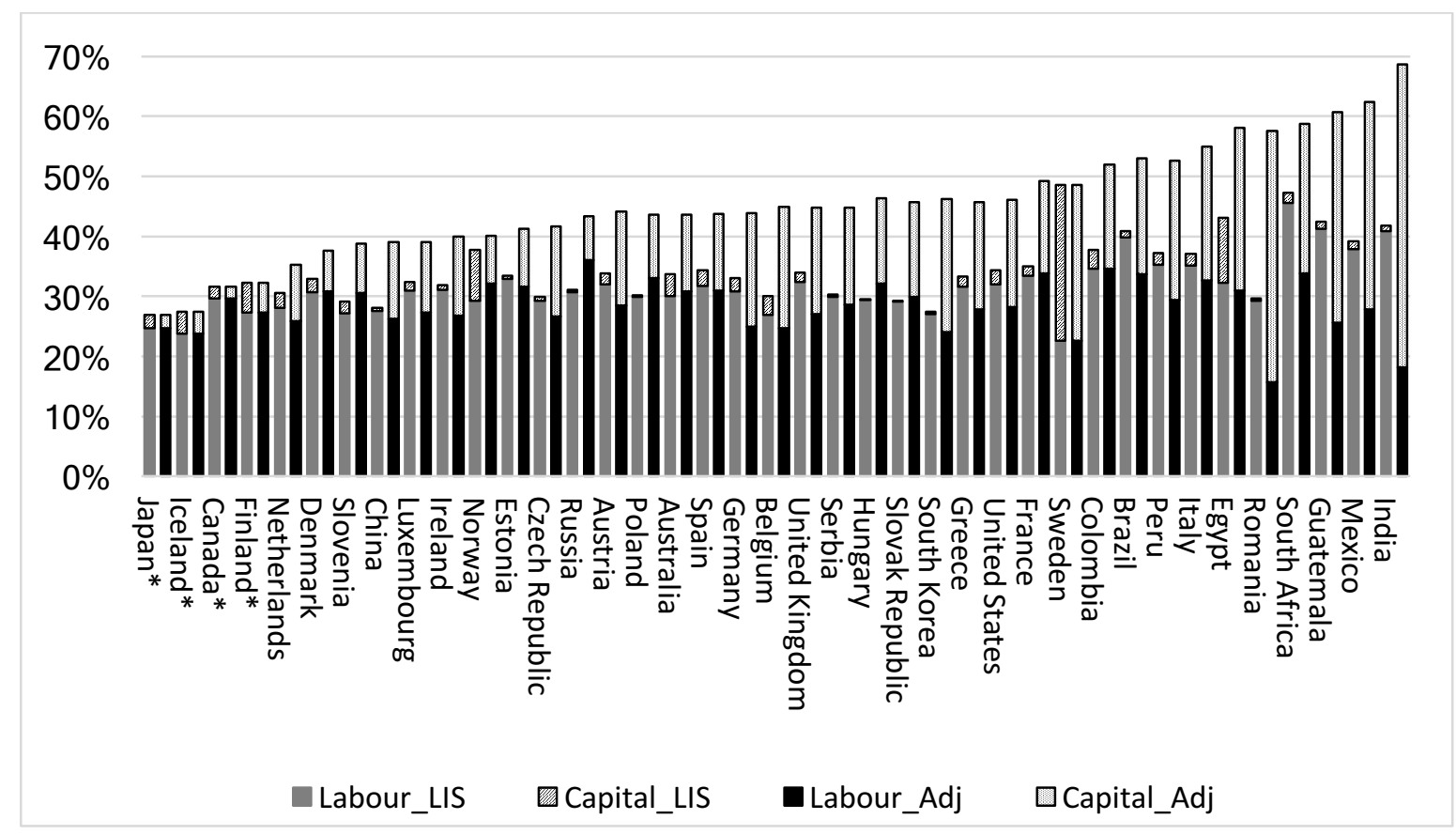

Notes: This graph shows the Top 10\% market income shares prior to and after the adjustment (in ascending order of the adjusted income share). Labour_LIS, Capital_LIS, Labour_adj and Capital_adj refer to the top LIS labor income share, top LIS capital income share, top adjusted labor income share and top adjusted capital income share, respectively. The figures represent the latest available data (see Table 1 for further details). In countries marked with an * the residual is negative so no adjustment has been made.

In general, the adjustment tends to be stronger in developing and Eastern and Southern European countries. This is expected given that rich countries tend to have more sophisticated household surveys that try to minimize underreporting at the top. Especially in Nordic countries the adjustment is either zero (Finland, Iceland and Sweden) or relatively small (Norway and 
Denmark). Other countries that have a relatively small residual are the Netherlands, Luxembourg, Estonia, and Ireland, whereas the countries with the largest adjustment are Romania, India, Mexico, South Korea, Guatemala and Italy. The average adjustment is 11 percentage points.

Figure 1 also shows that most of the adjustment takes place due to the capital income residual, which suggests that in most countries the Top 10\% especially underreport their capital income and/or that mainly top income households with high capital income are underrepresented in household surveys. However, despite the large capital income adjustment, labor income remains the main income source of the top decile in most countries. To be more precise, the pre-adjusted average share of capital income of Top 10\% market income is 3\%, while the postadjusted share increases to $17 \%$ (i.e., $83 \%$ of the top decile's market income still stems from employment). Moreover, the average Top 10\% capital income share as a percentage of total capital income changes from $46 \%$ to $80 \%$. Especially the latter figure seems reasonable. Capital income is strongly related to wealth holdings and Shorrocks et al. (2016) estimate that the richest $10 \%$ of the global population own approximately $89 \%$ of global wealth.

The Top 1\% income shares are presented in Figure 2. The ranking of the countries is similar to the ranking presented in Figure 1. Many of the obtained estimates are surprisingly high. This is especially true for India (47\%), Romania (38\%), the Latin American countries (30\% on average), and Egypt and South Africa (31\%). Again, the adjustment in Nordic Countries is relatively small, while the Top 1\% income share of Serbia, Peru, Slovakia, Italy, Hungary, Mexico, India, South Korea and Romania is adjusted by a factor greater than two. On average, the adjustment for the Top $1 \%$ is slightly stronger than the adjustment for the Top 10\% (12\%points vs. 11\%-points). This is expected given that the existing literature finds that especially the income of the very rich is underestimated in household surveys. 
Figure 2: Top 1\% market income shares

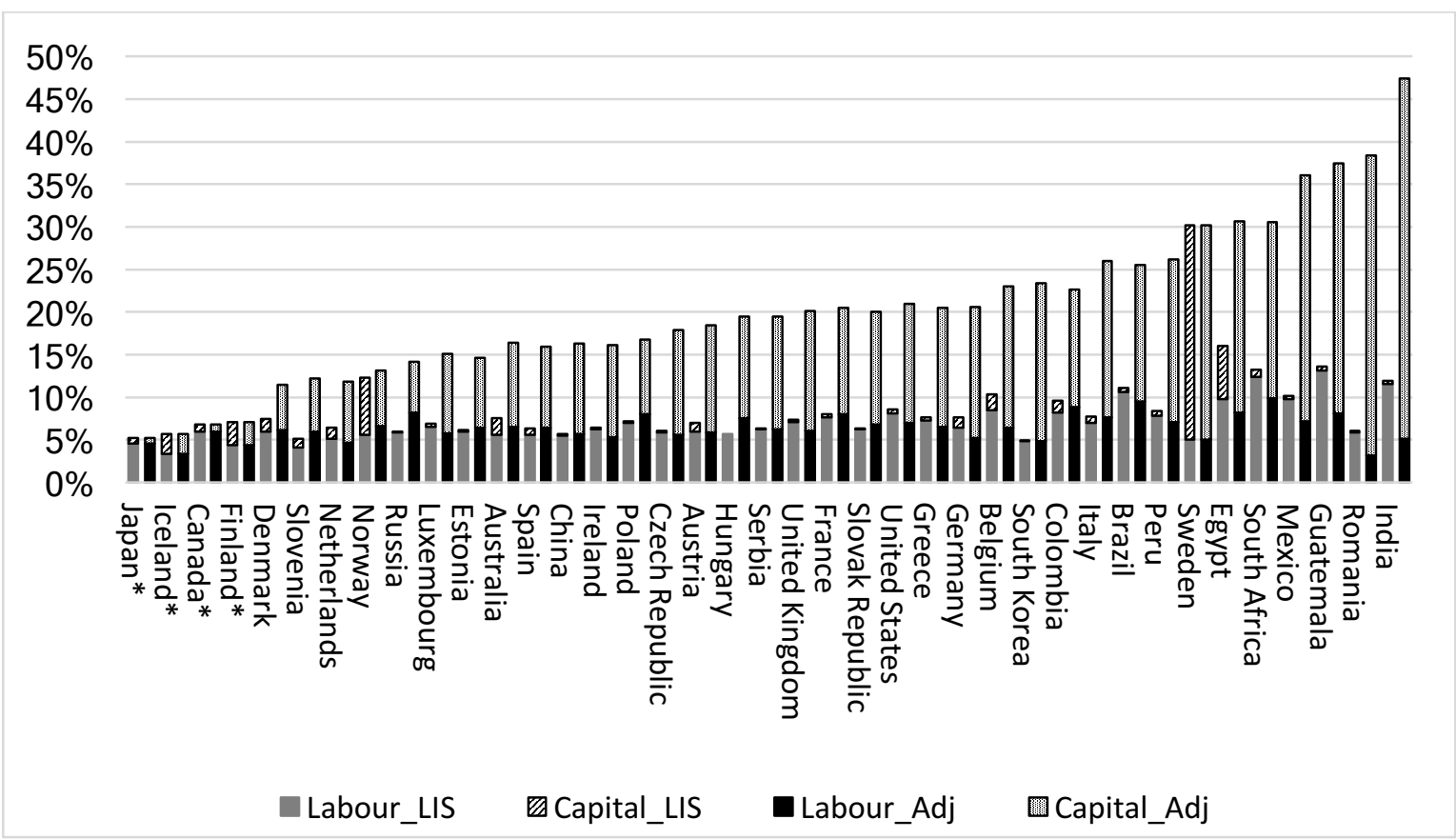

Notes: This graph shows the Top 10\% market income shares prior to and after the adjustment (in ascending order of the adjusted income share). See Figure 1 notes.

In line with the Top $10 \%$ estimates, the adjustment for the Top $1 \%$ occurs mainly due to the capital income residual. The average Top 1\% capital income share as a percentage of total capital income increases from $21 \%$ to $64 \%$. In other words, in nearly all sample countries the majority of capital incomes goes to the Top $1 \%$ according to the adjusted figures. This estimate appears extreme at first sight, however, in all countries the estimated Top 1\% capital income share is significantly lower than the $89 \%$ that is reported for Sweden in LIS's survey data. Moreover, this result is in line with the fact that wealth tends to be highly concentrated at the very top (see Goda (2017)). This adjustment also means that, in contrast to the Top $10 \%$, capital income becomes the main income source of the Top 1\% in most sample countries. Prior to the adjustment, capital income accounts for $13 \%$ of the total market income of the Top 1\%, while this figure rises to $62 \%$ after the adjustment. The finding that the main income source of the very rich is capital income seems reasonable. 


\subsection{Disposable income estimates}

On average, the disposable Top 10\% income share is 6 percentage points lower than the market income share, but the ranking of the most unequal countries is relatively similar (Figure 3). Especially in European countries, the estimated Top 10\% disposable income shares are much lower than the market income shares. The opposite is true for the Latin American countries, China and India, South Africa and Egypt, South Korea and Japan, Greece and Romania, and the USA. In other words, most countries with a relatively high degree of market income inequality have relatively low levels of redistribution, whereas countries with relatively low market income shares have relatively high degrees of redistribution. For the Top 1\% of disposable income the picture is very similar (Figure 4).

\section{Figure 3: Top 10\% disposable income shares}

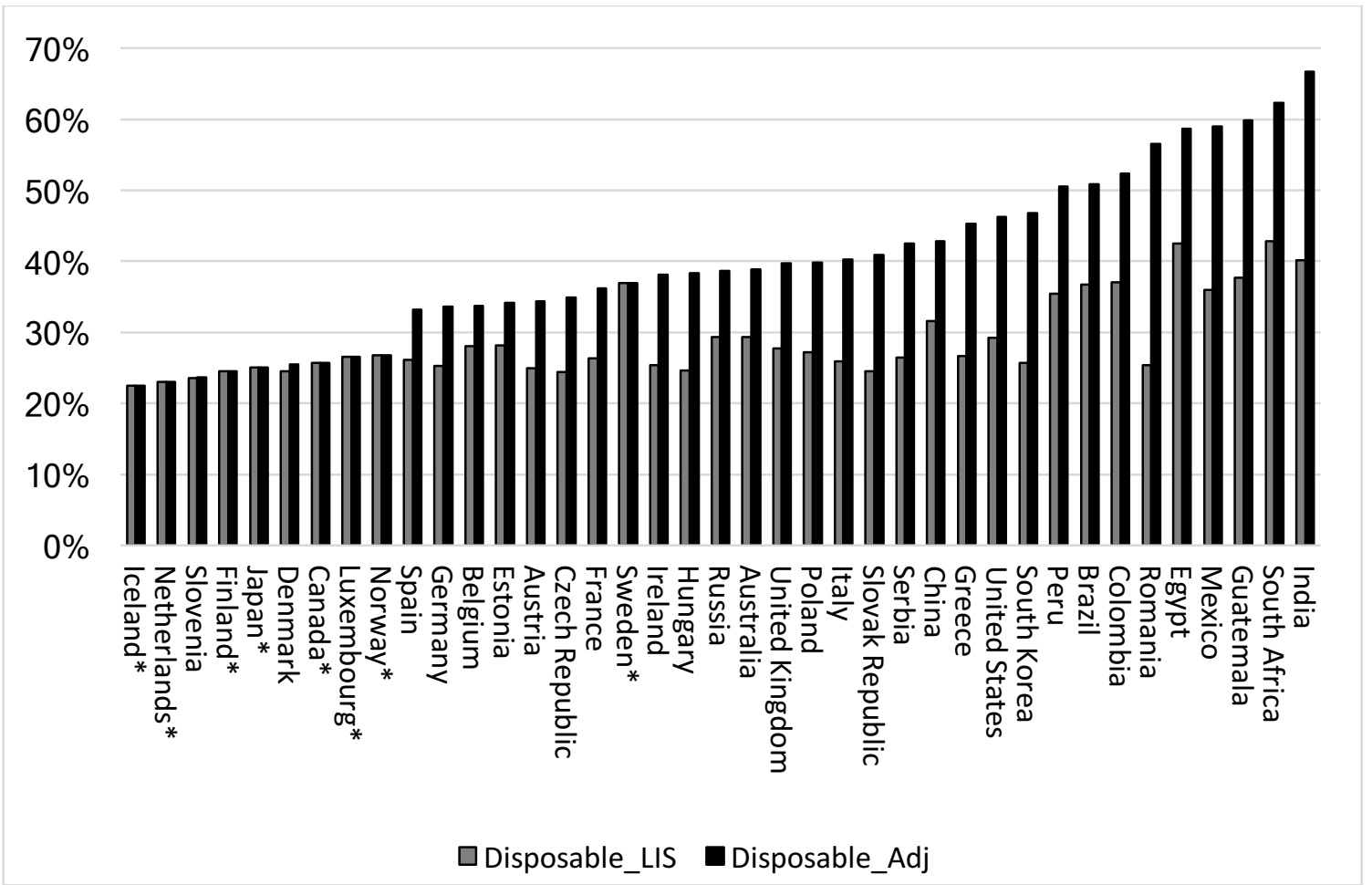

Notes: This graph shows the Top 10\% disposable income shares. LIS refers to the household survey data and Adjusted to the shares after the adjustment. See Figure 1 notes. 
Figure 4: Top 1\% disposable income shares

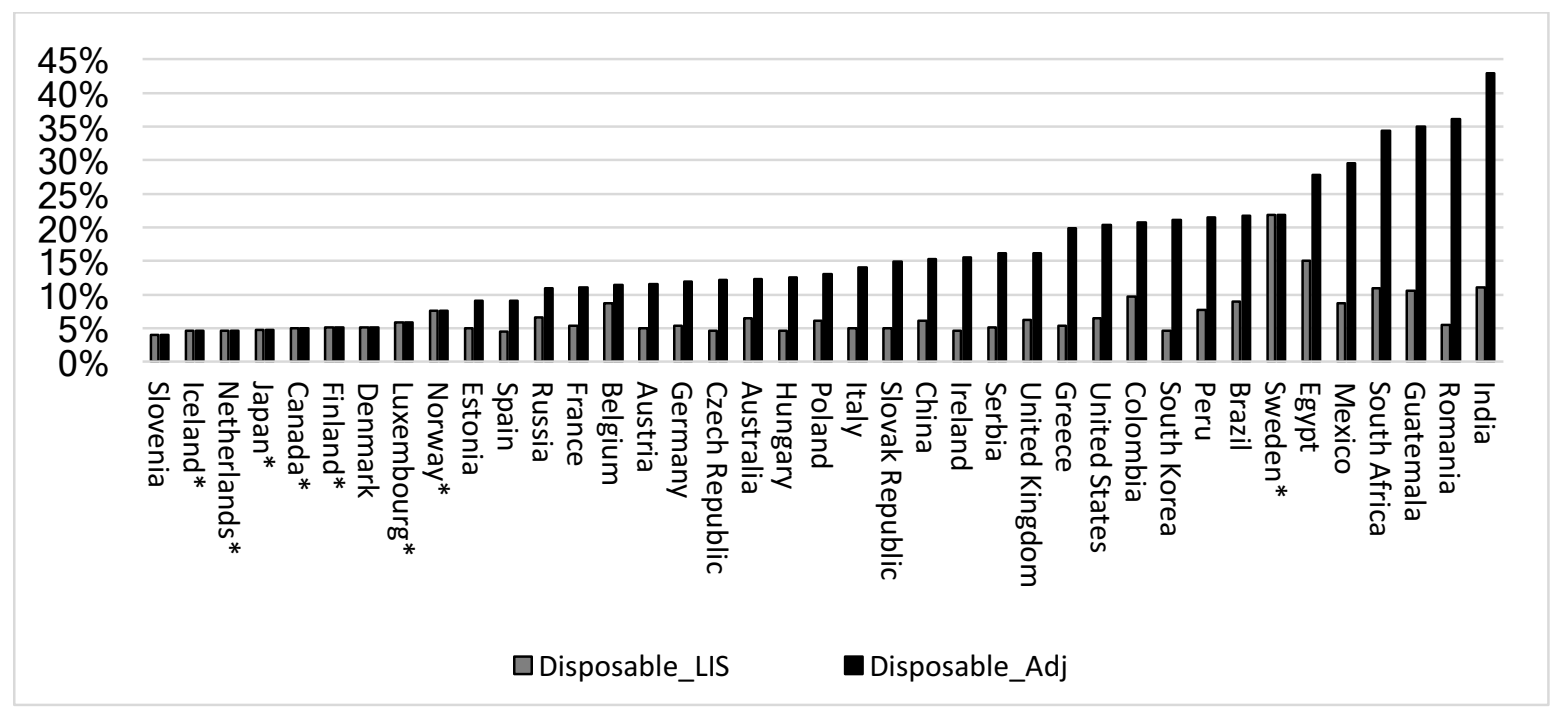

Notes: The upper and lower graph show the Top 1\% disposable income shares of our sample countries. Please see the notes to Figure 3 for further details.

The finding that countries with relatively high levels of market inequality tend to have relatively low levels of redistribution is paradoxical according to the median voter theorem because, in theory, most citizens of highly unequal countries have a relatively large incentive to vote for progressive tax and transfer systems (Breyer and Ursprung, 1998). However, this 'paradox' might be explained by fairness considerations (Alesina and Angeletos, 2005), mobility expectations (Piketty, 1995; Bénabou and Ok, 2001) or distinctive political institutions and the electoral and political system (Bradley et al., 2003; Iversen and Soskice, 2006; Mahler and Jesuit, 2006).

Finally, Table 2 compares the obtained disposable top income shares to WID's top income share estimates. It is important to note that the estimates are not one-hundred percent comparable because WID's estimates refer to pre-tax income whereas disposable income is post-tax income. However, this comparison should give a rough indication about the reliability of the estimated disposable income shares. At the time of writing this comparison could only be made for 18 countries of the sample, given that WID's estimates rely on tax data which is not available for most of our sample countries. 
Table 2: Obtained disposable top income shares vs. WID top income shares

\begin{tabular}{|c|c|c|c|c|}
\hline & Top $10 \% \%_{\text {Adjusted }}$ & Top $10 \%$ WID & Top $1 \%_{\text {Adjusted }}$ & Top $1 \%$ wID \\
\hline Australia & $44 \%$ & $30 \%$ & $16 \%$ & $9 \%$ \\
\hline Austria & $44 \%$ & & $18 \%$ & \\
\hline Belgium & $45 \%$ & & $23 \%$ & \\
\hline Brazil & $53 \%$ & & $26 \%$ & \\
\hline Canada* & $32 \%$ & $41 \%$ & $7 \%$ & $14 \%$ \\
\hline China & $39 \%$ & $38 \%$ & $16 \%$ & $12 \%$ \\
\hline Colombia & $52 \%$ & & $23 \%$ & $20 \%$ \\
\hline Czech Republic & $42 \%$ & & $18 \%$ & \\
\hline Denmark & $38 \%$ & $27 \%$ & $11 \%$ & $6 \%$ \\
\hline Egypt & $58 \%$ & & $31 \%$ & \\
\hline Estonia & $41 \%$ & & $15 \%$ & \\
\hline France & $32 \%$ & $30 \%$ & $7 \%$ & $8 \%$ \\
\hline Finland* & $49 \%$ & & $20 \%$ & \\
\hline Germany & $44 \%$ & $39 \%$ & $21 \%$ & $13 \%$ \\
\hline Greece & $46 \%$ & & $21 \%$ & \\
\hline Guatemala & $61 \%$ & & $37 \%$ & \\
\hline Hungary & $46 \%$ & & $19 \%$ & \\
\hline Iceland* & $27 \%$ & & $6 \%$ & \\
\hline India & $69 \%$ & & $47 \%$ & \\
\hline Ireland & $40 \%$ & $36 \%$ & $16 \%$ & $11 \%$ \\
\hline Italy & $55 \%$ & $34 \%$ & $26 \%$ & $9 \%$ \\
\hline Japan* & $27 \%$ & $42 \%$ & $5 \%$ & $11 \%$ \\
\hline Luxembourg & $39 \%$ & & $15 \%$ & \\
\hline Mexico & $62 \%$ & & $36 \%$ & \\
\hline Netherlands & $35 \%$ & $31 \%$ & $12 \%$ & $6 \%$ \\
\hline Norway & $40 \%$ & $28 \%$ & $13 \%$ & $8 \%$ \\
\hline Peru & $53 \%$ & & $26 \%$ & \\
\hline Poland & $44 \%$ & & $17 \%$ & \\
\hline Romania & $58 \%$ & & $38 \%$ & \\
\hline Russia & $43 \%$ & & $14 \%$ & \\
\hline Serbia & $45 \%$ & & $19 \%$ & \\
\hline Slovak Republic & $46 \%$ & & $20 \%$ & \\
\hline Slovenia & $39 \%$ & & $12 \%$ & \\
\hline South Africa & $59 \%$ & $65 \%$ & $31 \%$ & $19 \%$ \\
\hline South Korea & $46 \%$ & $45 \%$ & $23 \%$ & $12 \%$ \\
\hline Spain & $44 \%$ & $32 \%$ & $16 \%$ & $9 \%$ \\
\hline Sweden* & $49 \%$ & $30 \%$ & $30 \%$ & $9 \%$ \\
\hline United Kingdom & $45 \%$ & $41 \%$ & $20 \%$ & $15 \%$ \\
\hline United States & $46 \%$ & $46 \%$ & $21 \%$ & $19 \%$ \\
\hline
\end{tabular}

Notes: This table presents the obtained Top $10 \%$ and Top 1\% disposable income shares, and compares them with the fiscal top income shares reported in the WID database (2017). In cases where no WID data is available for the same year, the closest available year is taken as a benchmark. 
This comparison shows that in some cases the retrieved disposable top income share estimates are higher (Australia, China, France, Ireland, Italy, South Korea, and Sweden), in some cases they are almost identical (Colombia, Denmark, Norway, Spain, UK, and USA), and in some cases they are considerably lower (Canada, Germany, Japan and Netherlands) than WID's fiscal top income shares. In other words, our methodology seems to have neither a consistent upward nor downward bias. Interestingly, there is no clear pattern among the countries that are not adjusted. While Canada and Japan have significantly lower top income shares compared to those reported in WID, Sweden's are significantly higher. This finding is puzzling, considering that the household surveys of these countries at least partly rely on administrative tax records.

\section{Conclusions}

This paper is the first to adjust market and disposable top income shares that are reported in LIS with national accounts data. The non-reliance on tax data allows us to consider 39 developed and developing countries, of which 21 countries are currently not covered by the widely used World Wealth \& Income Database (WID). A further novelty of this study is the distinction between capital and labor income in the adjustment process.

The obtained results suggest that in most countries household surveys tend to underestimate top income shares significantly (especially in developing countries). Notable exceptions are the Nordic countries, Canada and Japan. Most of the top income adjustment occurs due to the underestimation of capital income. The average Top 10\% capital income share as a percentage of total capital income increases from $46 \%$ to $80 \%$ after the adjustment, while that of the Top $1 \%$ changes from $21 \%$ to $64 \%$. This adjustment seems reasonable, considering that wealth holdings are highly concentrated. A further credible outcome of the adjustment is that capital income becomes the main income source for the Top 1\%, whereas labor income remains the main income source for the Top $10 \%$.

With regard to the obtained disposable top income shares, we find that some are similar to the fiscal top income shares reported by WID, but that they are in many cases significantly higher or lower. Although these estimates are not one-hundred percent comparable, this finding suggests that our easy-to-implement methodology neither has an upward nor downward bias 
and thus seems especially suitable for countries in which no tax data is available. However, the presented estimates should be treated with some caution. It is not clear if some of the adjustments are excessively large or if they show that the true extent of inequality is vastly underestimated. In any case, the results suggest that there is an urgent need for more research on the topic and to improve the availability and quality of income data. Future research should, for example, try to consider country specific characteristics when using SNA data to estimate top income shares.

\section{References}

Acemoglu, D. and Robinson, J.A. (2008). Persistence of Power, Elites, and Institutions. American Economic Review, 98(1): 267-93.

Alesina, A. \& Angeletos, G.M. (2005). Fairness and Redistribution. American Economic Review, 95, 960-980.

Alvaredo, F., Atkinson, A.B., Chancel, L., Piketty, T., Saez, E., Zucman, G. (2017a). 'Distributional National Accounts (DINA) Guidelines: Concepts and Methods used in WID.world'. WID Working Paper, No. 2016/1, updated version from January $9^{\text {th }}$.

Alvaredo, F., Chancel, L., Piketty, T. Saez, E. and Zucman, G. (2017b). 'Global Inequality Dynamics: New Findings from WID.world'. NBER Working Paper, No. 23119.

Atkinson, A. B. (2007) Measuring Top Incomes: Methodological Issues. In: Atkinson, A.B. and Piketty, T. (eds.): Top Incomes over the Twentieth Century: A Contrast Between Continental European and English-Speaking Countries. Oxford: Oxford University Press.

Atkinson, A. and Piketty, T. (2007). Top Incomes over the Twentieth Century: A Contrast between Continental European and English-Speaking Countries (Volume 1). Oxford: Oxford University Press.

Atkinson, A. and Piketty, T. (2010). Top Incomes: A Global Perspective (Volume 2). Oxford: Oxford University Press.

Atkinson, A.B. (2015). Inequality: what can be done?. Cambridge: Harvard University Press.

Atkinson, A.B. and Brandolini, A. (2001). Promise and Pitfalls in the Use of 'Secondary' DataSets: Income Inequality in OECD Countries. Journal of Economic Literature, 39(3): 771799.

Atkinson, A.B. and Piketty, T. (2007). Top incomes over the twentieth century: A contrast between continental European and English-speaking countries. Oxford: Oxford University Press.

Atkinson, A.B. and Piketty, T. (2010.) Top incomes: A global perspective. Oxford: Oxford University Press. 
Atkinson, A.B., Piketty, T. and Saez, E. (2011). Top Incomes in the Long Run of History. Journal of Economic Literature, 49(1): 3-71.

Bénabou, R. \& Ok, E.A. (2001). Social mobility and the demand for redistribution: The POUM hypothesis. The Quarterly Journal of Economics, 447-487.

Bradley, D., Huber, E., Moller, S., Nielsen, F. \& Stephens, J. (Jan de 2003). Distribution and Redistribution in Postindustrial Democracies. World Politics, 55(2), 193-228.

Breyer, F. and Ursprung, H.W. (1998). Are the rich too rich to be expropriated?. Economic power and the feasibility of constitutional limits to redistribution. Public Choice, 94, 135156.

Campos Vázquez, R.M. and Chavez, E. (2016). 'Estimating top income shares without tax return data: Mexico since the 1990s'. Centro de Estudios Económicos del Colegio de Mexico, No. IV-2016.

Crotty, J.R. (2012). The great austerity war: what caused the US deficit crisis and who should pay to fix it?. Cambridge Journal of Economics, 36(1): 79-104.

Deaton, A. (2005). Measuring Poverty in a Growing World (Or Measuring Growth in a Poor World). Review of Economics and Statistics 87(1): 1-19.

Esteban, J. and D. Ray (2006). Inequality, Lobbying, and Resource Allocation. American Economic Review, 96(1): 257-79.

Gilens, M. and Page, B.I. (2014). Testing Theories of American Politics: Elites, Interest Groups, and Average Citizens. Perspectives on Politics, 12(3): 564-81.

Goda, T. (2016). Global trends in relative and absolute income inequality. Ecos de Economía: A Latin American Journal of Applied Economics, 20(42): 46-96.

Goda, T. (2017). The global concentration of wealth. Cambridge Journal of Economics, early online view, doi: 10.1093/cje/bex020.

Goda, T., Onaran, O. and Stockhammer, E. (2017). Income Inequality and Wealth Concentration in the Recent Crisis. Development and Change, 48(1): 3-27.

Groves, R.M. and Couper, M. (1998). Nonresponse in Household Interview Surveys. Wiley.

Halter, D., Oechslin, M. and Zweimüller, J. (2014). Inequality and growth: the neglected time dimension. Journal of Economic Growth, 19(1): 81-104.

Henry, J.S. (2012). 'The price of offshore revisited: New estimates for 'missing' global private wealth, income, inequality, and lost taxes'. Tax Justice Network Research Paper, $22^{\text {nd }}$ July.

Herzer, D. and Vollmer, S. (2012). Inequality and growth: evidence from panel cointegration. Journal of Economic Inequality, 10(4): 489-503.

Herzer, D. and Vollmer, S. (2013). Rising top incomes do not raise the tide. Journal of Policy Modeling, 35(4): 504-19

Iversen, T. \& Soskice, D. (2009). Distribution and Redistribution: The Shadow of the Nineteenth Century. World Politics, 61(3), 438-486. 
Kumhof, M., Ranciére, R. and Winant, P. (2015). Inequality, Leverage, and Crises. American Economic Review, 105(3):1217-1245.

Lagarde, C. (2013). 'A New Global Economy for a New Generation'. World Economic Forum Annual Meeting 2013, Davos, Switzerland, 23 January.

Lakner, C. and Milanovic, B. (2013). 'Global Income Distribution: From the Fall of the Berlin Wall to the Great Recession'. World Bank Policy Research Working Paper, No. 6719.

Lakner, C. and Milanovic, B. (2016). Global Income Distribution: From the Fall of the Berlin Wall to the Great Recession. World Bank Economic Review, 30(2): 203-232.

Leigh, A. (2007), How Closely Do Top Incomes Shares Track Other Measures of Inequality?. The Economic Journal, 117: F589-F603.

LIS (2017). LIS Database. Retrieved from http://www.lisdatacenter.org/our-data/lis-database/.

Mahler, V. \& Jesuit, D. (2006). Fiscal redistribution in the developed countries: new insights from the Luxembourg Income Study. Socio-Economic Review, 4(3): 483-511.

Obama, B.H. (2011). 'Remarks by the President on the Economy in Osawatomie, Kansas'. Osawatomie High School, Osawatomie, Kansas, USA, 06 December.

OECD (2015). In It Together: Why Less Inequality Benefits All. Paris: Organisation for Economic Co-operation and Development.

Onaran, O. and Galanis, G. (2014). Income distribution and growth: a global model. Environment and Planning A, 46(10): 2489-2513.

Oxfam (2014). Even it Up. Time to end extreme inequality. Oxford: Oxfam GB.

Oxfam (2017). An Economy for the 99\%. Oxford: Oxfam GB.

Palan, R., Murphy, R. and Chavagneux, C. (2010). Tax Havens: How globalization really works. New York: Cornell University Press.

Piketty, T. (1995). Social mobility and redistributive politics. The Quarterly Journal of Economics, 110(3): 551-584.

Piketty, T. (2014). Capital in the Twenty-First Century. Cambridge Mass: Belknap Press of Harvard University Press.

Piketty, T. (2015). Putting Distribution Back at the Center of Economics: Reflections on Capital in the Twenty-First Century. Journal of Economic Perspectives, 29(1): 67-88.

Ruiz, N. and Woloszko, N. (2016). 'What do households surveys suggest about the Top 1\% incomes and inequality in OECD countries?'. OECD Working Paper, No. ECO/WKP(2015)83.

Shorrocks, A., Davies, J., Lluberas, R. and Koutsoukis, A. (2016). Global Wealth Report 2016. Zurich: Credit Suisse Research Institute.

Stiglitz, J.E. (2012). The price of inequality. London: Penguin Books.

Stockhammer, E. (2015). Rising inequality as a cause of the present crisis. Cambridge Journal of Economics, 39(3): 935-958. 
West, S.A. (1986). Estimation of the Mean from Censored Income Data. American Statistical Association, Proceedings of the Section on Survey Research Methods: 665-670.

Wilkinson, R. and Pickett, K. (2011). The Spirit Level: Why Greater Equality Makes Societies Stronger. London: Bloomsbury Press.

Zucman, G. (2013). The Missing Wealth of Nations: Are Europe and the U.S. net debtors or net creditors?. Quarterly Journal of Economics, 128(3): 1321-1364.

Zucman, G. (2014). Taxing across Borders: Tracking Personal Wealth and Corporate Profits. Journal of Economic Perspectives, 28(4): 121-148. 